\title{
Paul Gorceix, Maurice Maeterlinck du mysticisme à la pensée ésotérique
}

\section{Ida Merello}

\section{Q OpenEdition}

1 Journals

\section{Edizione digitale}

URL: https://journals.openedition.org/studifrancesi/46192

DOI: 10.4000/studifrancesi.46192

ISSN: 2421-5856

\section{Editore}

Rosenberg \& Sellier

\section{Edizione cartacea}

Data di pubblicazione: 1 octobre 2007

Paginazione: 471-472

ISSN: 0039-2944

\section{Notizia bibliografica digitale}

Ida Merello, «Paul Gorceix, Maurice Maeterlinck du mysticisme à la pensée ésotérique», Studi Francesi

[Online], 152 (LI | II) | 2007, online dal 30 novembre 2015, consultato il 24 novembre 2021. URL: http:// journals.openedition.org/studifrancesi/46192 ; DOI: https://doi.org/10.4000/studifrancesi.46192

Questo documento è stato generato automaticamente il 24 novembre 2021.

\section{(c) (i) (9)}

Studi Francesi è distribuita con Licenza Creative Commons Attribuzione - Non commerciale - Non opere derivate 4.0 Internazionale. 


\title{
Paul Gorceix, Maurice Maeterlinck du mysticisme à la pensée ésotérique
}

\author{
Ida Merello
}

\section{NOTIZIA}

PAUL GORCEIX, Maurice Maeterlinck du mysticisme à la pensée ésotérique, Paris, Eurédit 2006, 2 voll.

L'opera è divisa in due volumi, di cui il primo costituito da un saggio che fa da introduzione al secondo, e quest'ultimo ci offre un'antologia di testi (Onirologie, Le Miracle des mères, Joyzielle, La Princesse Isabelle, Les Fiançailles). L'A. propone il suo studio come una riflessione sul percorso spirituale di Maeterlinck, ma in realtà fa ben di più, compiendo come fase introduttiva una discesa in profondità nel milieu simbolista belga, sia artistico che letterario, che si rivela, esattamente come quello francese, un crogiolo di tendenze apparentemente opposte (esoteriche e scientifiche), ma in realtà strettamente legate le une alle altre. Il punto di vista di Maeterlinck diventa il mezzo per offrire una visione unitaria; per questo il milieu francese è preso in considerazione soltanto nei suoi rapporti con quello belga. È qui che l'A. mostra tutta la sua finezza e competenza critica, attraverso un'esplorazione sia delle riviste esoteriche («Le mouvement littéraire») che dei movimenti («L'art idéaliste») cui hanno dato origine, offrendoci anche una fine analisi dell'esoterismo di Iwan Gilkin, del pittore Jean Delville e dell'incisore Félicien Rops. Concede quindi un largo spazio a Max Elskamp, descrivendone il percorso spirituale che l'ha condotto al buddismo, sulla scorta di un'ampia documentazione di prima mano e critica, nonché del catalogo della sua biblioteca, quale testimone delle sue conoscenze, da Schopenhauer ai testi buddisti, e quindi delle evoluzioni del suo pensiero. Se l'interpretazione di Schopenhauer in chiave spiritualista, o in direzione buddista, era anche caratteristica dei milieux esoterici francesi, l'A. intravede la ricerca di una trascendenza anche nell'amore di Elskamp per l'arte orientale cinese e giapponese. Forse si sarebbe dovuto sottolineare il fatto che si tratti di un legame del tutto interno a Elskamp, determinato dal valore simbolico che 
attribuisce agli oggetti, in quanto in generale il giapponesismo, ben diffuso in Francia, era rappresentativo soprattutto di un ideale ornamentale e decorativo.

2 Quando l'A. affronta il pensiero di Maeterlinck, l'ambiente artistico e letterario circostante è già perfettamente delineato, permettendo di comprendere meglio la specificità e l'originalità dello scrittore, in rapporto con le tendenze del momento. In quest'ambito l'A. mette anche in evidenza i legami con la Francia e l'importanza di autori francesi come Villiers, che, malgrado le sue deboli conoscenze filosofiche, era capace di suscitare grandi entusiasmi; o Huysmans, che gli suggerì, con il suo À rebours, la traduzione di Ruysbroeck, già tentata, ma malamente, da Hello. Solo dopo questa complessa messa in prospettiva l'A. procede all'analisi di Onirologie (1889), messo in rapporto con il Miracle des Mères (1944), a lui tanto distante temporalmente quanto vicino per soggetto (la telepatia), nonché di Joyzelle, La Princesse Isabelle et Les Fiançailles. Vengono evidenziati i rapporti con l'idealismo tedesco a proposito dell'elaborazione della teoria dell'immaginazione creatrice (teoria di moda del resto tra fine Ottocento e inizio Novecento, praticata sia dagli occultisti che dagli scienziati, come Théodule Ribot, che le dedicò un saggio), ma altrettanta attenzione viene concessa alla problematica della crisi d'identità, di cui si individuano le suggestioni esoteriche e della psichiatria dinamica. 